\title{
Short communication: Production of antihypertensive peptide HLPLP by enzymatic hydrolysis: Optimization by response surface methodology
}

\author{
A. Quirós, B. Hernández-Ledesma, M. Ramos, P. J. Martín-Álvarez, and I. Recio ${ }^{1}$ \\ Institute of Food Science Research (CIAL, CSIC-UAM), Nicolás Cabrera 9, 28049 Madrid, Spain
}

\begin{abstract}
This study evaluates the potential ability of proteolytic enzymes to release the antihypertensive peptide HLPLP, $\beta$-casein $\mathrm{f}(134-138)$, from caseinate. Corolase PP (Röhm GmbH \& Co. KG, Darmstadt, Germany) was found as the most appropriate enzyme to produce this peptide. The optimization of the main experimental variables involved in the process [concentration of Corolase PP, concentration of Peptidase 433P (Biocatalysts Ltd., Parc Nantgarw, UK), and the hydrolysis time on the HLPLP concentration, expressed as area of peak] were studied using a central composite face design. The optimum conditions to obtain the maximum concentration of HLPLP provided by the statistical program were a concentration of Corolase PP of $60 \mathrm{mg} / \mathrm{g}$ of protein and hydrolysis time of $24 \mathrm{~h}$. The use of the Peptidase 433P did not increase the amount of the active peptide. The obtained hydrolysate might be used as functional ingredient with antihypertensive properties.
\end{abstract}

Key words: response surface methodology, caseinate, antihypertensive peptide, enzymatic hydrolysis

\section{Short Communication}

Fermentation is one of the main approaches used to release antihypertensive peptides from milk proteins. Our group has demonstrated that different strains of Enterococcus faecalis are able to produce fermented milks with potent antihypertensive activity in spontaneously hypertensive rats, after short- and longterm intake (Miguel et al., 2005, 2006; Muguerza et al., 2006). Peptide LHLPLP, corresponding to $\beta$-CN $\mathrm{f}(133-138)$, has been identified as one of the major peptides responsible for the antihypertensive activities of the fermented milk produced (Quirós et al., 2007). Bioavailability studies using Caco-2 cells have shown that this peptide is hydrolyzed by cellular peptidases to pep-

Received February 22, 2012.

Accepted March 10, 2012.

${ }^{1}$ Corresponding author: i.recio@csic.es tide HLPLP before the transport across the intestinal epithelium (Quirós et al., 2008). When administrated to spontaneously hypertensive rats, peptide HLPLP decreased both systolic and diastolic blood pressure (Miguel et al., 2010), indicating its ability to resist enzymatic digestion and to be absorbed, reaching target organs in an intact and active form. van Platerink et al. (2006) have also detected this peptide in human plasma after oral administration, which demonstrates its intestinal absorption in humans. Previous results in our laboratory have shown that peptide HLPLP from human $\beta$-CN was formed after digestion of human milk with pepsin and pancreatin (Hernández-Ledesma et al., 2007).

In spite of Enterococcus being present in different fermented foods, such as cheese, sausages, and olives, and some strains of this microorganism currently being considered as probiotics (Foulquié Moreno et al., 2006), its use in the food industry is still very controversial because of its pathogenic potential (Franz et al., 2011). Several advantages of enzymatic hydrolysis, such as the low cost of production of peptides, as well as the feasibility of their incorporation and handling into a variety of foodstuffs, make this strategy a perfect alternative to fermentation (del Mar Contreras et al., 2011b).

Response surface methodology (RSM) has been widely used to optimize conditions of fermentation and hydrolysis processes. In the last few years, different studies have demonstrated the value of this technique in the production of food protein hydrolysates with potent biological activities (Guerard et al., 2007; Ren et al., 2008). Recently, del Mar Contreras et al. (2011a) have applied RSM to optimize hydrolysis conditions of a whey protein concentrate enriched in $\beta$-LG with thermolysin, with the purpose of obtaining the most potent antioxidant hydrolysate. Similarly, Tavares et al. (2011) used this technique to optimize hydrolysis of whey protein concentrate, $\alpha$-LA, and casein macropeptide by an aqueous extract of Cynara cardunculus, using degree hydrolysis, antioxidant power, and angiotensin-converting enzyme (ACE) inhibitory activity as response variables. Therefore, RSM would be a good strategy to optimize production of antihypertensive peptide HLPLP from casein. 
The objective of this study was to evaluate the production of antihypertensive peptide HLPLP by enzymatic hydrolysis of caseinate with different enzymes. Hydrolysis conditions, including the type and concentration of enzymes, and the incubation time were optimized by RSM.

Aqueous solutions of $5 \%$ (wt/vol) of sodium caseinate (Induxtra de Suministros Llorella SA, Gerona, Spain) were equilibrated at $37^{\circ} \mathrm{C}$ and their $\mathrm{pH}$ adjusted to 7 to 8 with $0.5 \mathrm{~N} \mathrm{NaOH}$. Chymotrypsin [Enzyme Commission (EC) no. 3.4.21.1, type I-S, $44 \mathrm{U} / \mathrm{mg}$ of protein; Sigma Chemical Co., St. Louis, MO], Corolase PP (Röhm GmbH \& Co. KG, Darmstadt, Germany) and Pancreatin 4XNF-P211P (Biocatalysts Ltd., Parc Nantgarw,
UK) were added at an enzyme:substrate $(\mathbf{E}: \mathbf{S})$ ratio of 20, 40, and $60 \mathrm{mg}$ of enzyme/g of protein, respectively. In addition, Peptidase 433P (Biocatalysts Ltd.) was added in some experiments at different E:S between 0 and $20 \mathrm{mg} / \mathrm{g}$ of protein. For hydrolysis with pepsin (EC 3.4.23.1, type A, $10.000 \mathrm{U} / \mathrm{mg}$; Sigma Chemical Co.), sodium caseinate was dissolved $(2.5 \% \mathrm{wt} / \mathrm{vol})$ in $50 \mathrm{~m} M$ sodium citrate-citric acid buffer ( $\mathrm{pH} 2.5)$, and pepsin was added at an E:S ratio of $20 \mathrm{mg}$ of enzyme/g of protein. Hydrolysis samples were incubated at $37^{\circ} \mathrm{C}$ for $24 \mathrm{~h}$. Aliquots were withdrawn at $0,30,60,120$, 180, $300 \mathrm{~min}$, and $24 \mathrm{~h}$. Enzymes were inactivated by heating at $95^{\circ} \mathrm{C}$ for 15 min. Pepsin was inactivated by raising the $\mathrm{pH}$ to 7.0 with $1 \mathrm{M} \mathrm{NaOH}$.

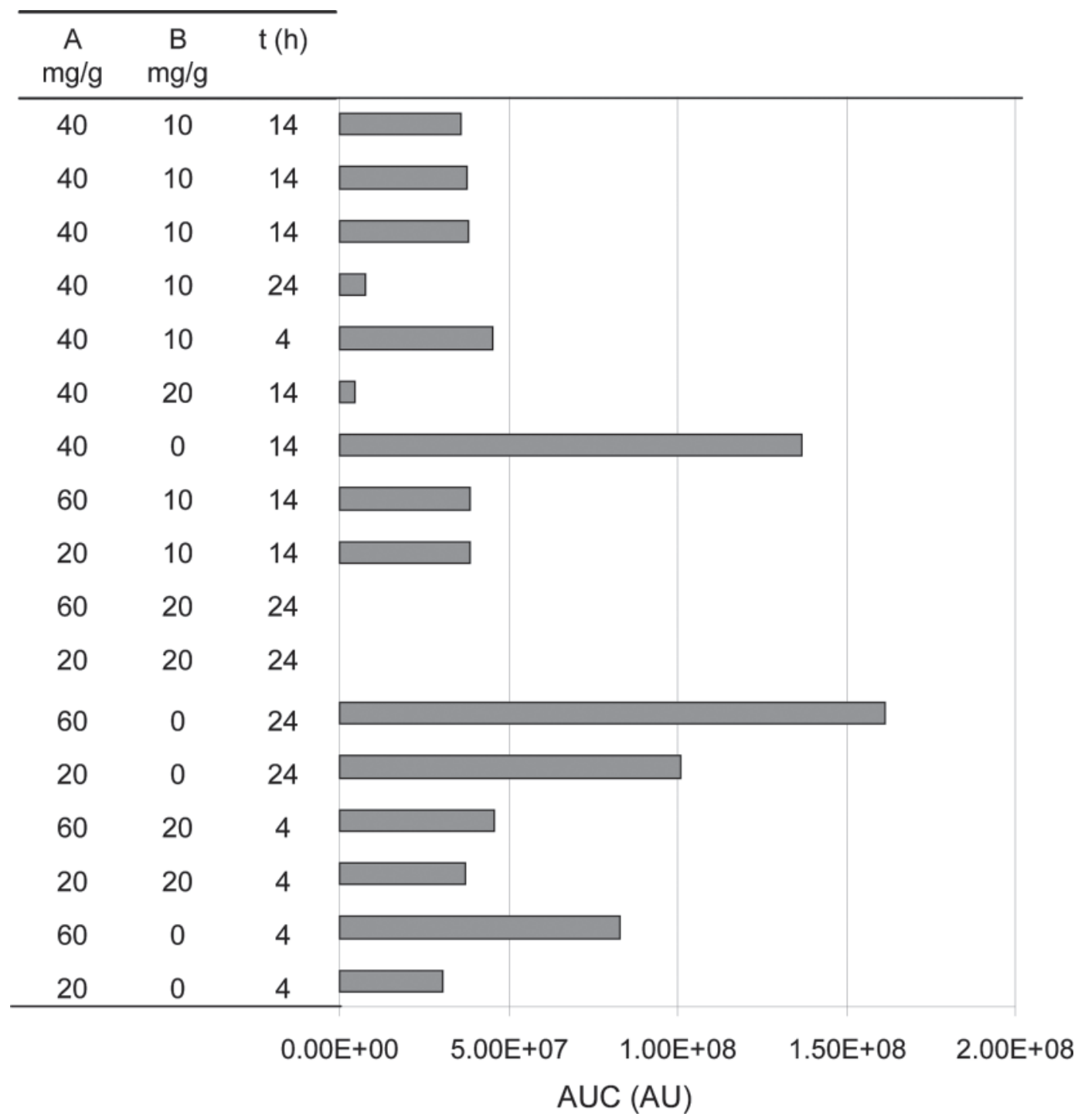

Figure 1. Experimental matrix design for the factors concentration of Corolase PP (Röhm GmbH \& Co. KG, Darmstadt, Germany; A) and Peptidase 433P (Biocatalysts Ltd., Parc Nantgarw, UK; B), and incubation time (t), and results obtained for the response variable (peptide HLPLP concentration expressed as area of peak). AUC $=$ area under the curve. 


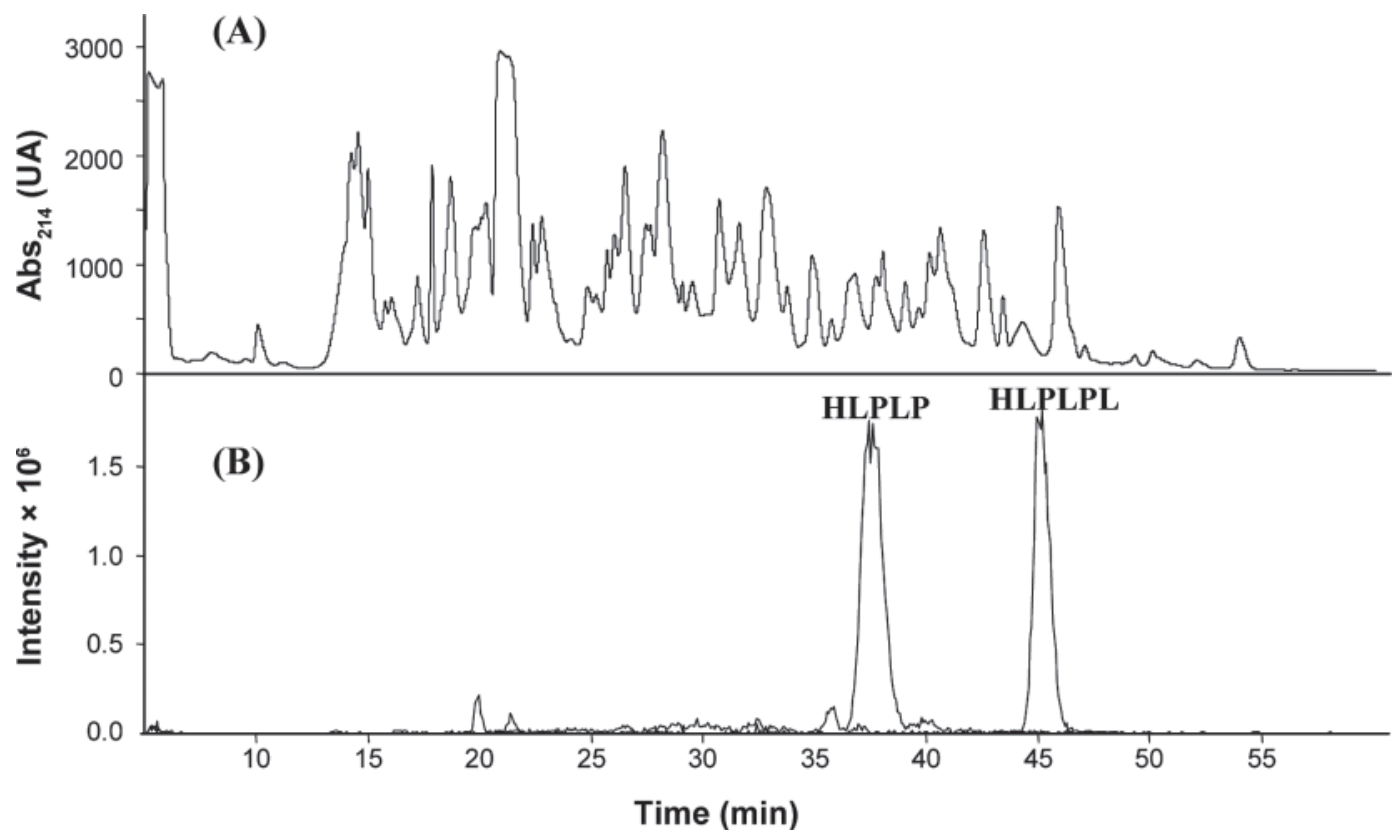

Figure 2. (A) Ultraviolet chromatogram of sodium caseinate hydrolysate with Corolase PP (Röhm GmbH \& Co. KG, Darmstadt, Germany) after 24-h incubation. (B) Extracted ions corresponding to peptide HLPLP $(m / z$ 576.3) and peptide HLPLPL $(m / z 689.4)$. Abs $214=$ absorbance at 214-nm wavelength.

Hydrolysate samples with different enzymes were analyzed by reverse-phase HPLC-tandem mass spectrometry (RP-HPLC-MS/MS) on an Agilent 1100 HPLC system (Agilent Technologies, Waldbronn, Germany), connected online to an Esquire-LC quadrupole ion trap instrument (Bruker Daltonik GmbH, Bremen, Germany), following the method of Quirós et al. (2008), with some modifications. The column used in these experiments was a $150 \mathrm{~mm} \times 2.1 \mathrm{~mm}$ Inertsil 5 ODS-3 $\mathrm{C}_{18}$ column with a particle size of $5 \mu \mathrm{m}$ (Varian BV, Bergen op Zoom, the Netherlands), and the injection volume was $50 \mu \mathrm{L}$. Samples were eluted with a linear gradient of solvent B (acetonitrile-trifluoroacetic acid, 1000:0.27, vol/vol) in solvent A (water-trifluoroacetic acid, 1000:0.37, vol/vol) from 0 to $45 \% \mathrm{~B}$ in $60 \mathrm{~min}$.

After selection of the enzyme, the effect of 3 factors: concentration of Corolase PP (A), concentration of Peptidase 433P (B), and hydrolysis time ( $\mathrm{t}$ ), on the HLPLP amount was studied using a central composite face design. A total of 17 experiments: 8 points of a full factorial design, 6 star points placed on the faces of the sides, and 3 center points to estimate the experimental errors, were carried out in randomized run order. By using this design, the 3 variables were tested at 3 different experimental levels: Corolase PP at 20, 40, and 60 $\mathrm{mg} / \mathrm{g}$ of protein; Peptidase $433 \mathrm{P}$ at 0,10 , and $20 \mathrm{mg} / \mathrm{g}$ of protein; and time of 4,14 , and $24 \mathrm{~h}$, corresponding to the coded levels $-1,0$, and +1 , respectively. The response variable selected was the HLPLP concentration (expressed as area of peak). Figure 1 shows the experimental matrix design, with the experimental levels of the independent variables (factors), along with the results obtained for the response analyzed variables. The quadratic polynomial model proposed for the response variable $\left(Y_{i}\right)$ was

$$
\begin{aligned}
Y_{i}= & \beta_{0}+\beta_{1} \mathrm{~A}+\beta_{2} \mathrm{~B}+\beta_{3} \mathrm{t}+\beta_{1,1} \mathrm{~A}^{2}+\beta_{2,2} \mathrm{~B}^{2}+\beta_{3,3} \mathrm{t}^{2} \\
& +\beta_{1,2} \mathrm{~A} \times \mathrm{B}+\beta_{1,3} \mathrm{~A} \times \mathrm{t}+\beta_{2,3} \mathrm{~B} \times \mathrm{t}+\varepsilon_{i},
\end{aligned}
$$

where $\beta_{0}$ is the intercept; $\beta_{i}$ are the linear coefficients; $\beta_{i, i}$ are the quadratic coefficients; $\beta_{i, j}$ are the interaction coefficients; and $\varepsilon_{i}$ is the error variable. The parameters of the model were estimated by multiple linear regression (MLR) using the Modde 5.0 program (Umetrics AB, Umeå, Sweden; http://www.umetrics.com). The effect of the each term in the model and its statistical significance was analyzed from the ANOVA table. The terms not significantly different from zero $(P>0.10)$, were excluded of the model and the mathematical model was refitted by MLR. The goodness of fit of the model was evaluated by the coefficient of determination $\left(\mathrm{R}^{2}\right)$, the residual standard deviation (RSD), and the predictive power of the MLR model $\left(\mathbf{Q}^{2}\right.$ value), which is based on the prediction residual sum of squares using a crossed validation procedure. From the new fitted 


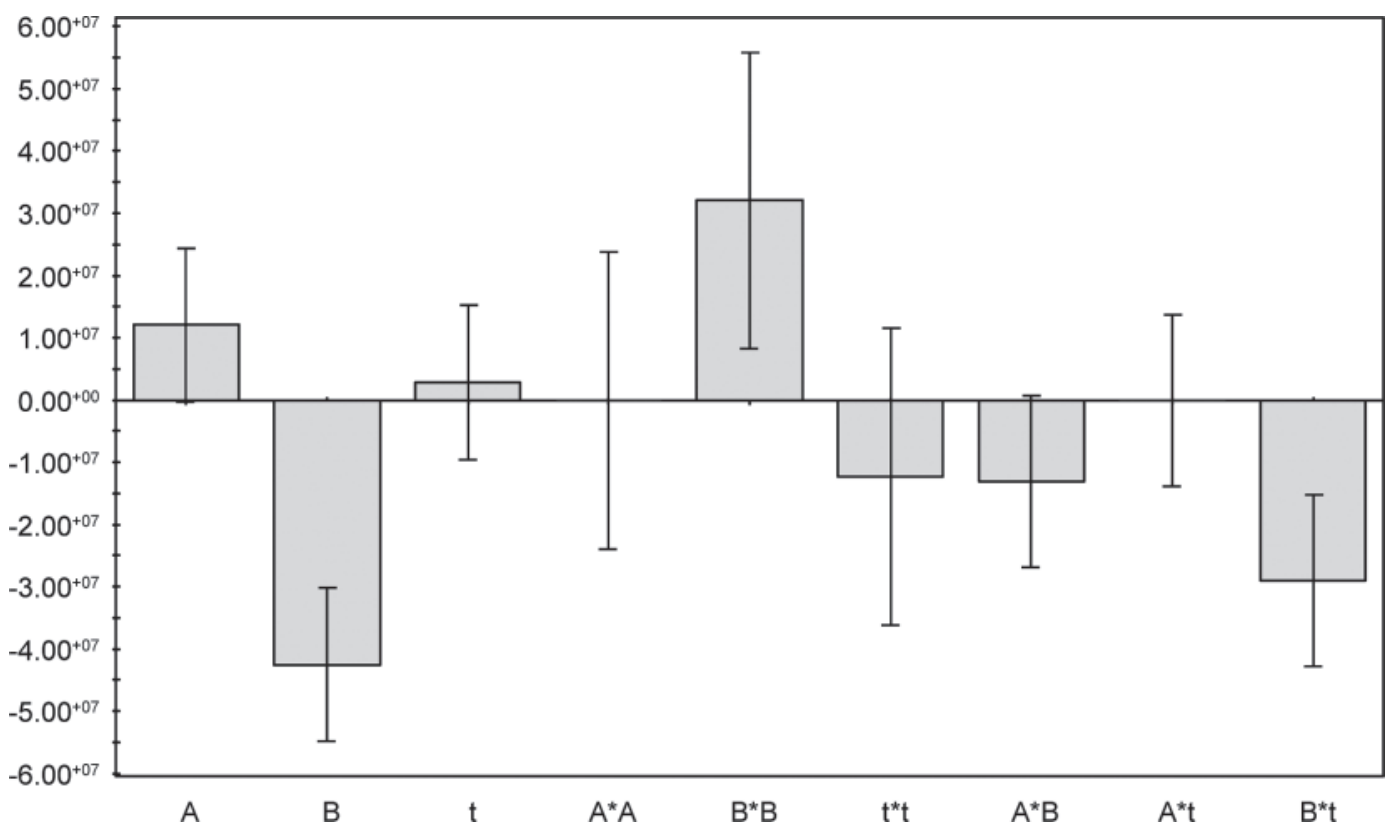

Figure 3. Plot of normalized regression coefficient values for centered and scaled factors $[\mathrm{A}=\mathrm{Corolase} \mathrm{PP}$ (Röhm GmbH \& Co. KG, Darmstadt, Germany), B = Peptidase 433P (Biocatalysts Ltd., Parc Nantgarw, UK), and $t=$ hydrolysis time], and their 90\% confidence intervals, obtained from multiple linear regression (MLR), for the response variable (peptide HLPLP concentration expressed as area of peak).

model, the surface plot of response surface and the optimum conditions that maximized the response variable were obtained.

To find the best protease to liberate the antihypertensive peptide HLPLP, different enzymes (pepsin, chymotrypsin, Corolase PP, and Pancreatin 4XNF-P211P) were used to hydrolyze sodium caseinate at their sug-

Table 1. Regression coefficients for unscaled factors and statistics for the fit, obtained from multiple linear regression for the analyzed response variable (peptide HLPLP concentration expressed as area of peak)

\begin{tabular}{lc}
\hline Item $^{1}$ & $\begin{array}{c}\text { Regression } \\
\text { coefficient }\end{array}$ \\
\hline Terms of the model & \\
Constant & $7,741,863.00$ \\
$\mathrm{~A}$ & $1,258,758.00$ \\
$\mathrm{~B}$ & $-2,706,018.50^{* *}$ \\
$\mathrm{t}$ & $3,182,095.00$ \\
$\mathrm{~B} \times \mathrm{B}$ & $256,217.97^{*}$ \\
$\mathrm{~A} \times \mathrm{B}$ & $-65,381.42$ \\
$\mathrm{~B} \times \mathrm{t}$ & $-289,966.06^{* *}$ \\
$\mathrm{Statistics}$ for goodness of fit of the model & 0.90 \\
$\mathrm{R}^{2}$ & 0.702 \\
$\mathrm{RSD}$ & $18,549,482$ \\
$\mathrm{Q}^{2}$ & \\
\hline${ }^{1} \mathrm{~A}=$ Corolase PP (Röhm GmbH \& Co. KG, Darmstadt, Germany); \\
$\mathrm{B}=$ Peptidase 433P (Biocatalysts Ltd., Parc Nantgarw, UK); $\mathrm{t}=$ \\
hydrolysis time; RSD = residual standard deviation; $\mathrm{Q}^{2}=$ power of \\
prediction of the fitted model. \\
$*$ Regression coefficient significantly different from zero $(P<0.05)$; \\
$* *$ regression coefficient significantly different from zero $(P<0.01)$.
\end{tabular}

gested optimal conditions. The obtained hydrolysates at different times were analyzed by HPLC-MS/MS to identify the antihypertensive sequence. Peptide HLPLP and its precursor peptide HLPLPL were not identified in the hydrolysates obtained after incubation with pepsin or chymotrypsin. However, hydrolysis with Pancreatin 4XNF-P211P or Corolase PP for $1 \mathrm{~h}$ allowed the release of these peptides, whose concentration was increasing until the end of the hydrolysis reaction $(24 \mathrm{~h})$. As an example, Figure 2A shows the UV chromatogram of the hydrolysate with Corolase PP at $24 \mathrm{~h}$, and Figure $2 \mathrm{~B}$ shows the extracted ions corresponding to peptide HLPLP, with an $m / z$ of 576.3 , and peptide HLPLPL, with an $m / z$ of 689.4.

Corolase PP was found to be the most appropriate enzyme to obtain the antihypertensive peptide HLPLP. To optimize the production process of this peptide, sodium caseinate was incubated with Corolase PP and Peptidase 433P. This last enzyme, of fungal origin, was included in the study because of its ability to hydrolyze amino acids from the $\mathrm{N}$ - and C-terminal. Peptidase $\mathrm{P} 433 \mathrm{P}$ would be able to hydrolyze Leu residue from peptide HLPLPL, increasing the concentration of the active form of the peptide HLPLP. A factorial design was used to optimize conditions of the hydrolytic process, evaluating the effect of 3 factors [i.e., concentration of Corolase PP (A), concentration of Peptidase 433P (B), and incubation time (t)]. As mentioned earlier, Figure 1 shows the values of the concentration 


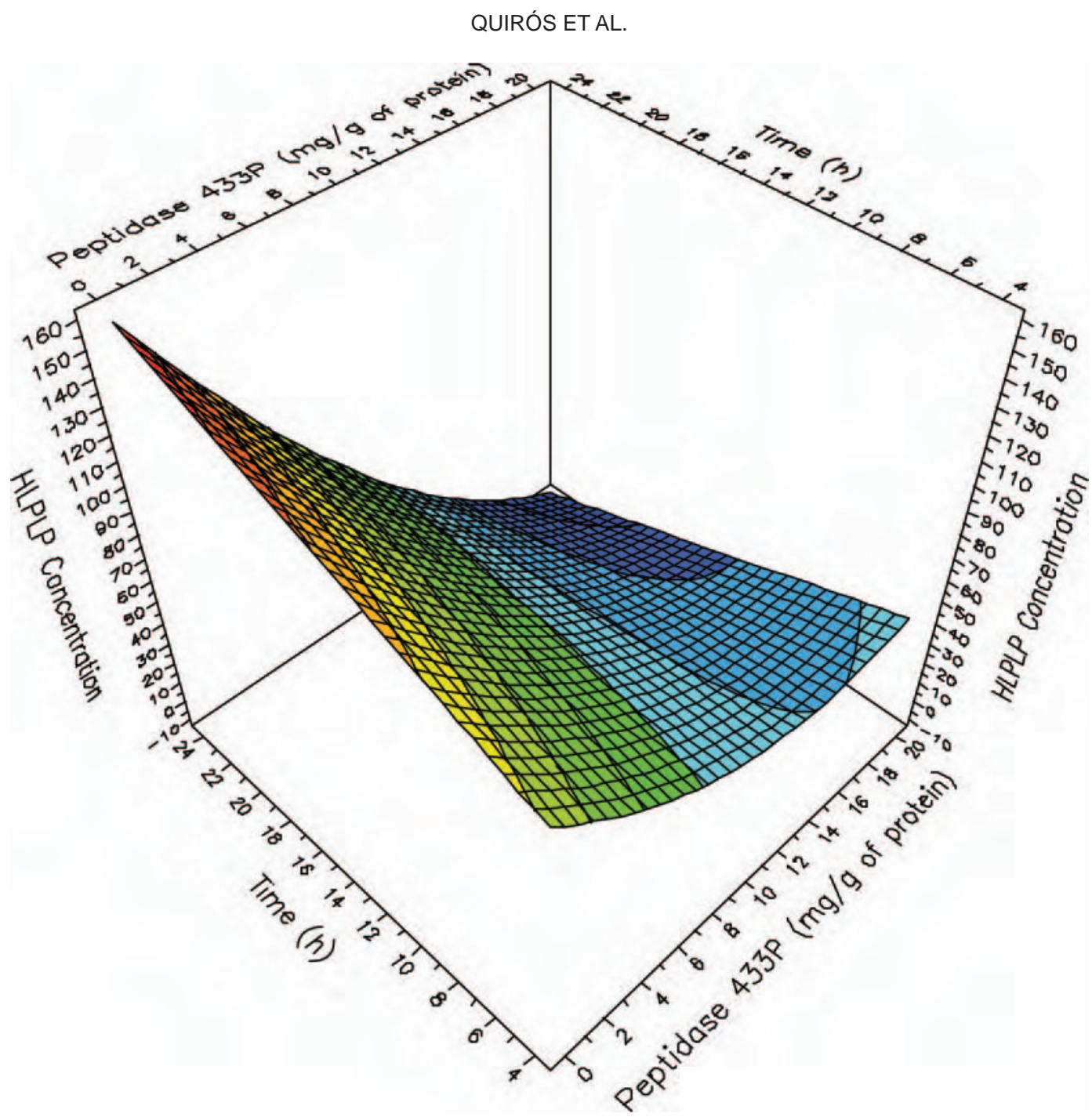

Figure 4. Surface plot of the concentration of peptide HLPLP for a concentration of enzyme Corolase PP (Röhm GmbH \& Co. KG, Darmstadt, Germany) of $60 \mathrm{mg} / \mathrm{g}$ of protein. Color version available in the online PDF.

of peptide HLPLP, expressed as area of the peak, obtained for all of the experiments, corresponding to the matrix design with the experimental levels of the 3 factors. Multiple linear regression was applied to estimate the parameters of the proposed model in Equation 1 for the response variable. Figure 3 shows the estimated regression coefficients of the model for the centered and scaled factors and their $90 \%$ confidence levels, illustrating the importance and the statistical significance of the different terms in the model. It can be seen (Figure $3)$ that the terms significantly different from zero $(P<$ $0.10)$ that have the strongest influence in the response variable are $\mathrm{B}$, their quadratic terms $(\mathrm{B} \times \mathrm{B})$, and the interaction term $\mathrm{B} \times \mathrm{t}$, and that the terms $\mathrm{A} \times \mathrm{A}, \mathrm{A} \times$ $\mathrm{t}$, and $\mathrm{t} \times \mathrm{t}$ can be eliminated from the model.

From the statistical significance of the estimated regression coefficients, the terms of the model not sig- nificantly different from zero $(P>0.10)$ were excluded from Equation 1 and the mathematical model was refitted by MLR. The new results are listed in Table 1, and they include the following information: the regression coefficients obtained for unscaled factors, and the statistics for goodness of fit of the model: $\mathrm{R}^{2}, \mathrm{RSD}$, and $\mathrm{Q}^{2}$ value. From these results, the following conclusions can be drawn: the estimated model was found adequate enough to describe the data, the fraction of variation of the response variable explained by the model $\left(\mathrm{R}^{2}\right)$ was 0.9 , and the power of prediction value (0.7 or larger) indicates that the model has good predictive ability and will have small prediction errors. Figure 4 shows the surface of the response variable (concentration of peptide HLPLP) as a function of concentration of enzyme Peptidase 433P and time, for a concentration of Corolase PP of $60 \mathrm{mg} / \mathrm{g}$ of protein. The optimum conditions 
of the design to obtain the maximum concentration of peptide HLPLP, provided by the statistical program, were the following: a concentration of Corolase $\mathrm{PP}$ of $60 \mathrm{mg} / \mathrm{g}$ of protein, without the use of Peptidase 433P, and a hydrolysis time of $24 \mathrm{~h}$. The predicted value for the response variable for these optimum conditions was $1.596 \times 10^{8}$, close to the observed value $\left(1.615 \times 10^{8}\right)$.

In summary, our results show that sodium caseinate is a good raw material for Corolase PP-mediated production of the antihypertensive peptide HLPLP, which might be commercially attractive and valued as a functional ingredient in the food industry. Although clinical trials with obtained hydrolysates are needed to confirm their antihypertensive activity in humans, previous results for fermented milk containing similar concentrations of LHLPLP may anticipate its functionality.

\section{ACKNOWLEDGMENTS}

This work received financial support from projects AGL2008-01713 and Consolider Ingenio 2010 FUNCC-Food CSD2007-00063, AGL2011-24643 (Ministry of Economy and Competitiveness, Spain) and P2009/ AGR-1469 (Autonomous Community of Madrid, Spain). B. Hernández-Ledesma thanks the Spanish National Research Council (CSIC, Madrid, Spain) for her Ramón y Cajal contract.

\section{REFERENCES}

del Mar Contreras, M., B. Hernández-Ledesma, L. Amigo, P. J. Martín-Álvarez, and I. Recio. 2011a. Production of antioxidant hydrolyzates from a whey protein concentrate with thermolysin: Optimization by response surface methodology. LWT-Food Sci. Technol. 44:9-15.

del Mar Contreras, M., M. A. Sevilla, J. Monroy-Ruiz, L. Amigo, B. Gómez-Sala, M. Ramos, and R. Recio. 2011b. Food-grade production of an antihypertensive casein hydrolysate and resistance of active peptides to drying and storage. Int. Dairy J. 21:470-476.
Foulquié Moreno, M. R., P. Sarantinopoulos, E. Tsakalidou, and L. De Vuyst. 2006. The role and application of enterococci in food and health. Int. J. Food Microbiol. 106:1-24.

Franz, C. M. A. P., M. Huch, H. Abriouel, W. Holzapfel, and A. Gálvez. 2011. Enterococci as probiotics and their implications in food safety. Int. J. Food Microbiol. 151:125-140.

Guerard, F., M. T. Sumaya-Martinez, D. Laroque, A. Chabeaud, and L. Dufossé. 2007. Optimization of free radical scavenging activity by response surface methodology in the hydrolysis of shrimp processing discards. Process Biochem. 42:1486-1491.

Hernández-Ledesma, B., A. Quirós, L. Amigo, and I. Recio. 2007. Identification of bioactive peptides after digestion of human milk and infant formula with pepsin and pancreatin. Int. Dairy J. $17: 42-49$.

Miguel, M., J. Á. Gómez-Ruiz, I. Recio, and A. Aleixandre. 2010. Changes in arterial blood pressure after single oral administration of milk-casein derived peptides. Mol. Nutr. Food Res. 54:14221427.

Miguel, M., B. Muguerza, E. Sánchez, M. A. Delgado, I. Recio, M. Ramos, and A. Aleixandre. 2005. Changes in arterial blood pressure in hypertensive rats caused by long-term intake of milk fermented by Enterococcus faecalis CECT 5728. Br. J. Nutr. 94:36-43.

Miguel, M., I. Recio, M. Ramos, M. A. Delgado, and M. A. Aleixandre. 2006. Antihypertensive effect of peptides obtained from Enterococcus faecalis-fermented milk in rats. J. Dairy Sci. 89:3352-3359.

Muguerza, B., M. Ramos, E. Sánchez, M. A. Manso, M. Miguel, A. Aleixandre, M. A. Delgado, and I. Recio. 2006. Antihypertensive activity of milk fermented by Enterococcus faecalis strains isolated from raw milk. Int. Dairy J. 16:61-69.

Quirós, A., A. Dávalos, M. A. Lasunción, M. Ramos, and I. Recio. 2008. Bioavailability of the antihypertensive peptide LHLPLP: Transepithelial flux of HLPLP. Int. Dairy J. 18:279-286.

Quirós, A., M. Ramos, B. Muguerza, M. A. Delgado, M. Miguel, A. Aleixandre, and I. Recio. 2007. Identification of novel antihypertensive peptides in milk fermented with Enterococcus faecalis. Int. Dairy J. 17:33-41.

Ren, J. Y., M. Zhao, J. Shi, J. Wang, Y. Jiang, C. Cui, Y. Kakuda, and S. Jun Xue. 2008. Optimization of antioxidant peptide production from grass carp sarcoplasmic protein using response surface methodology. LWT-Food Sci. Technol. 41:1624-1632.

Tavares, T. G., M. M. Contreras, M. Amorim, P. J. Martín-Álvarez, M. E. Pintado, I. Recio, and F. X. Malcata. 2011. Optimisation, by response surface methodology, of degree of hydrolysis and antioxidant and ACE-inhibitory activities of whey protein hydrolysates obtained with cardoon extract. Int. Dairy J. 21:926-933.

van Platerink, C. J., H.-G. M. Janssen, R. Horsten, and J. Haverkamp. 2006. Quantification of ACE inhibiting peptides in human plasma using high performance liquid chromatography-mass spectrometry. J. Chromatogr. B Analyt. Technol. Biomed. Life Sci. 830:151-157. 